\title{
Study of Serum Insulin Level in Hypertensive Patients
}

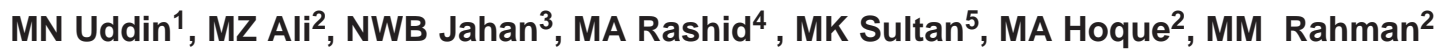 \\ ${ }^{1}$ Department of Clinical Biochemistry, NICVD, Dhaka, ${ }^{2}$ Department of Cardiology, NICVD, Dhaka, \\ ${ }^{3}$ NICVD, Dhaka, ${ }^{4}$ Biomedical Research Group, BIRDEM, Dhaka, ${ }^{5}$ Department of Clinical \\ Biochemistry, NICVD, Dhaka.
}

Keywords: Serum Insulin; Hypertension

\begin{abstract}
:
Background and aims: Hypertension is a frequent and almost ubiquitous health disorder, prevalent both in developed and developing countries. Hyperinsulinemia and insulin resistance have been suggested to be closely associated with the pathogenesis of essential hypertension. However there is considerable controversy in this regards. The present study was designed to explore the relationship between serum insulin and serum ionized calcium in non diabetic and diabetic hypertensive subjects.

Subjects and Methods: A total of 57 hypertensive and diabetic hypertensive patients attending out patients department of the BIRDEM and NICVD were included in the study. Fasting serum glucose was measured by glucose oxidase method, lipid profile was measured by enzymatic method. Serum insulin was measured by Enzyme Linked Immunosorbent assay (ELISA) method and serum ionized calcium by the Ion Sensitive Electrode (ISE) technique.

Results: Glucose-insulin ratios were calculated as the index for insulin. Serum insulin (pmol/ml), Mean $\pm S D, 147 \pm 48$ in DC and $170 \pm 80$ in DH groups vs $118 \pm 21$ in NC and $120 \pm 41$ in EH groups, $p=0.023$ and $p=0.031$ respectively. Although, from the serum insulin results, the diabetic groups seemed to have insulin resistance, the glucose-insulin ratios in the two groups were significantly

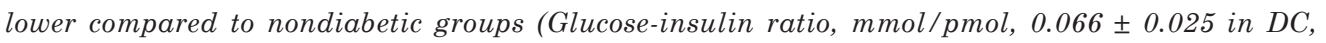
$0.074 \pm 0.025$ in $\mathrm{DH}$ vs $0.044 \pm 0.11$ in NC, $0.043 \pm 0.012$ in $\mathrm{EH}, p=0.005-0.0001)$. The serum ionized calcium in the healthy subject, first time reported in the country by an up to date method (1.17 \pm 0.05 $M \pm S D)$, were within the range found in healthy subjects of the other populations. No significant difference in the serum $\mathrm{Ca}^{2+}$ could be found between any of the study groups. Also, serum $\mathrm{Ca}^{2+}$ did not correlate with blood pressure, glucose or insulin in any of the study groups or with all the patients as a whole. Serum total cholesterol, triglyceride, HDLc and LDLc levels in the DC, EH and $D H$ group did not show any significant difference compared to NC group and among the groups. The lipid abnormality as reflected by the mean LDL-HDL cholesterol ratios was the highest in the DH group but the differences were not statistically significant compared to the NC, DC and EH group.

Conclusions: The data suggest the following conclusions: a) Serum ionized calcium level in our population is similar to that reported for other population. b) Serum glucose and insulin by themselves do not have any direct influence on serum ionized calcium. c) Non obese diabetes mellitus subjects in our population do not show insulin resistance as the primary defect. Rather, there is significant decompensation of the insulin secretory capacity in the subjects. d) Insulin resistance should be measured directly in relation to blood pressure and $\mathrm{Ca}^{2+}$ in appropriate groups of subjects to explore the relationship between insulin resistance, hyperinsulinemia and serum ionized calcium.
\end{abstract}

(Cardiovasc.j. 2011; 4(1): 13-16)

\section{Introduction:}

Hypertension is a frequent and almost ubiquitous health disorder, prevalent both in developed and developing countries. ${ }^{1}$ In United Kingdom about $50 \%$ of all deaths are attributable to cardiovascular diseases and of these at least $50 \%$ are due to hypertension. It is observed with concern that the incidence of hypertension is in increasing in the developing countries; and in Bangladesh an almost similar trend was reported by Malik. ${ }^{2}$ Among civilian population $92-94 \%$ of hypertensive patients belong to essential hypertension ${ }^{3}$. Several epidemiological studies also outlined a relationship between blood pressure and calcium in etiopathogenesis of hypertension. ${ }^{4-5}$ The low extracellular $\mathrm{Ca}^{2+}$ is attributed to increase intracellular $\mathrm{Ca}^{2+}$ uptake, which ultimately causes increase in peripheral vascular resistance leading

Address of correspondence - Dr Md. Nasir Uddin, Assistant Professor, Department of Clinical Biochemistry, National Institute of Cardiovascular Diseases (NICVD), Dhaka, Bangladesh. 
to hypertension. Low serum calcium level in hypertensive patients reported by some workers. ${ }^{6}$ Others have shown no significant relationship between serum ionized calcium and blood pressure in black hypertensive. ${ }^{7}$

Hyperinsulinemia and insulin resistance have been suggested to be closely associated with the pathogenesis of essential hypertension. ${ }^{7-8}$ However there is considerable controversy in this regards. ${ }^{9}$ It has been shown that insulin attenuates the receptor mediated $\mathrm{Ca}^{2+}$ influx and stimulates the activity of $\mathrm{Ca}^{2+}$-ATPase in vascular smooth muscle cells. These effect are blunted in insulin resistance. ${ }^{10}$ Several studies have shown that insulin resistance rather than hyperinsulinemia may be more closely associated essential hypertension. Recent study showed that essential hypertension is also an insulin resistance state, associated with hyperinsulinemia and exaggerated insulinemic responses to oral glucose load has led some authors to a causal relation of insulin in the pathophysiology of essential hypertension. However, circulating insulin level may be significantly lower in NIDDM compared with weight matched nondiabetic subjects suggested that factors other than insulin may be relevant as well. In Bangladesh now-a-days a considerable number of people are suffering from hypertension. Morbidity and mortality from this disease as also alarming. There was no detail study on serum insulin level and hypertensive patients in Bangladeshi population. In the above context the present study was designed to find out the relationship between glucose, insulin and serum ionized calcium in non diabetic and diabetic hypertensive subjects.

\section{Material and Methods:}

A total of 57 hypertensive and diabetic hypertensive patients attending out patients department of the BIRDEM and NICVD were included in the study. Twenty seven normal control and diabetic control matched for age, sex, body mass index (BMI) were selected from hospital visitors and medical personnel as control. Subjects with acute and chronic diabetic complications, history of hepatic renal and endocrine disease or any other systemic disease, antihypertensive drugs and pregnancy were excluded. The clinical and biochemical characteristics of these subjects are shown in Table I \& Table II respectivrly. After selection all subjects were advised to keep fasting overnight and not to smoke or take any medicine on the previous day. Fasting blood sample were collected and serum glucose measured by glucose oxidase method, serum total protein, albumin, creatinine and lipid profile measured by enzymatic method. Serum insulin was measured by Enzyme Linked Immunosorbent assay (ELISA) method and serum ionized calcium by the Ion Sensitive Electrode (ISE) using NOVA-8 Electrolytes Autoanalyzer. Results are expressed as mean \pm SD. All the statistical analysis was performed using SPSS package for windows. To compare the results between two groups, unpaired student's t- test was done.

\section{Results:}

All subjects were divided in to four groups according to the glycemic and blood pressure status in to Normal Control (NC), Diabetic Control (DC), Essential Hypertensive (EH) and Diabetic Hypertensive (DH). Clinical features and glycemic status and serum ionized calcium level of the study subjects are shown in (Table-I and Table-II).

\section{Table-I}

Clinical features of the study subjects

\begin{tabular}{lcccc}
\hline Group & Age & BMI & SBP $(\mathrm{mmHg})$ & DBP $(\mathrm{mmHg})$ \\
\hline $\mathrm{NC}(\mathrm{n}=15)$ & $38 \pm 4$ & $24.9 \pm 2.5$ & $110 \pm 7$ & $75 \pm 5$ \\
$\mathrm{DC}(\mathrm{n}=12)$ & $40 \pm 3$ & $23.7 \pm 2.5$ & $115 \pm 13$ & $74 \pm 5$ \\
$\mathrm{EH}(\mathrm{n}=18)$ & $39 \pm 4$ & $23.8 \pm 2.2$ & $141 \pm 10$ & $99 \pm 4$ \\
DH (n= 12) & $40 \pm 4$ & $24.0 \pm 3.3$ & $139 \pm 11$ & $97 \pm 3$ \\
t/p values & & & & \\
NC vs DC & $-1.75 / 0.093$ & $1.19 / 0.247$ & $-1.32 / 0.204$ & $0.09 / 0.93$ \\
NC vs EH & $-1.22 / 0.230$ & $1.32 / 0.197$ & $-10.36 / 0.0001$ & $1.32 / 0.197$ \\
NC vs DH & $-164 / 0.115$ & $0.75 / 0.462$ & $-7.90 / 0.0001$ & $-14.40 / 0.0001$ \\
DC vs EH & $0.45 / 0.658$ & $-0.06 / 0.949$ & $-5.91 / 0.0001$ & $-14.25 / 0.0001$ \\
DC vs DH & $-0.11 / 0.916$ & $-0.24 / 0.815$ & $-4.83 / 0.0001$ & $-14.84 / 0.0001$ \\
EH vs DH & $-0.50 / 0.620$ & $-0.21 / 0.83$ & $0.69 / 0.513$ & $1.07 / 0.298$ \\
\hline
\end{tabular}

BMI; body mass index, SBP; systolic blood pressure, DBP; diastolic blood pressure. Results are expressed as mean \pm SD. Statistical difference- calculated between two groups by unpaired student's 't' test. 
Glucose-insulin ratios were calculated as the index for insulin. Serum glucose was significantly higher in both diabetic control and diabetic hypertensive groups compared to the other two non diabetic groups. In parallel with glucose, hyperinsulinemia was observed only in the diabetic groups. Serum insulin(pmol $/ \mathrm{ml})$, Mean $\pm \mathrm{SD}, 147 \pm 48$ in DC and $170 \pm 80$ in $\mathrm{DH}$ groups vs $118 \pm 21$ in $\mathrm{NC}$ and $120 \pm$ 41 in $\mathrm{EH}$ groups, $\mathrm{p}=0.023$ and $\mathrm{p}=0.031$ respectively. Although, from the serum insulin results, the diabetic groups seemed to have insulin resistance, the glucose-insulin ratios in the two groups were significantly lower compared to nondiabetic groups (Glucose-insulin ratio, $\mathrm{mmol} /$ pmol, $0.066 \pm 0.025$ in DC, $0.074 \pm 0.025$ in $\mathrm{DH}$ vs $0.044 \pm 0.11$ in $\mathrm{NC}, 0.043 \pm 0.012$ in $\mathrm{EH}, \mathrm{p}=0.005$ $0.0001)$. The serum ionized calcium in the healthy subject, first time reported in the country by an up to date method $(1.17 \pm 0.05 \mathrm{M} \pm \mathrm{SD})$, were within the range found in healthy subjects of the other populations. No significant difference in the serum $\mathrm{Ca}^{2+}$ could be found between any of the study groups. Also, serum $\mathrm{Ca}^{2+}$ did not correlate with blood pressure, glucose or insulin in any of the study groups or with all the patients as a whole.

\section{Lipid levels of the study subjects}

Lipid levels of the study subjects are described in Table-III. Serum total cholesterol, triglyceride, HDLc and LDLc levels in the DC, EH and DH group did not show any significant difference compared to NC group and among the groups. LDL-HDL cholesterol ratio was calculated and an increasing value of LDL-HDL cholesterol ratios in DC, EH and DH group were observed. The lipid abnormality as reflected by the mean LDL-HDL cholesterol ratios was the highest in the $\mathrm{DH}$ group but the differences were not statistically significant compared to the NC, DC and EH group.

\section{Table-II}

Glycemic status and serum ionized calcium of the study subjects

\begin{tabular}{lcccc}
\hline Group & FSG $(\mathrm{mmol} / \mathrm{l})$ & FSInsulin $(\mathrm{pmol} / \mathrm{l})$ & Gl/In $(\mathrm{mmol} / \mathrm{pmol})$ & Calcium $(\mathrm{mmol} / \mathrm{l})$ \\
\hline $\mathrm{NC}(\mathrm{n}=15)$ & $5.01 \pm 0.78$ & $118 \pm 21$ & $0.044 \pm 0.011$ & $1.17 \pm 0.05$ \\
$\mathrm{DC}(\mathrm{n}=12)$ & $9.15 \pm 3.5$ & $147 \pm 48$ & $0.066 \pm 0.025$ & $1.17 \pm 0.07$ \\
$\mathrm{EH}(\mathrm{n}=18)$ & $4.82 \pm 0.84$ & $120 \pm 41$ & $0.043 \pm 0.012$ & $1.22 \pm 0.153$ \\
$\mathrm{DH}(\mathrm{n}=12)$ & $11.01 \pm 3.75$ & $170 \pm 80$ & $0.074 \pm 0.026$ & $1.15 \pm 0.03$ \\
t/p values & & & & \\
$\mathrm{NC}$ vs DC & $-4.37 / 0.0001$ & $-2.06 / 0.05$ & $-3.07 / 0.005$ & $-0.28 / 0.78$ \\
$\mathrm{NC}$ vs EH & $0.65 / 0.522$ & $-0.14 / 0.889$ & $0.10 / 0.928$ & $-125 / 0.222$ \\
$\mathrm{NC}$ vs DH & $-6.34 / 0.0001$ & $-2.43 / 0.023$ & $-4.11 / 0.0001$ & $0.92 / 0.336$ \\
DC vs EH & $4.96 / 0.0001$ & $1.59 / 0.127$ & $3.31 / 0.003$ & $0.50 / 0.619$ \\
DC vs DH & $-1.42 / 0.169$ & $-0.87 / 0.396$ & $-0.80 / 0.434$ & $174 / 0.098$ \\
EH vs DH & $-5.87 / 0.0001$ & $-2.27 / 0.031$ & $-4.42 / 0.0001$ & $1.44 / 0.161$ \\
\hline
\end{tabular}

FSG; fasting serum glucose, g/in; glucose insulin ratio.

Results are expressed as mean \pm SD. Statistical difference- calculated between two groups by unpaired student's 't' test.

Table-III

Lipid levels of the study subjects

\begin{tabular}{lccccc}
\hline Group & TChol $(\mathrm{mg} / \mathrm{dl})$ & TG $(\mathrm{mg} / \mathrm{dl})$ & HDLC $(\mathrm{mg} / \mathrm{dl})$ & LDLC $(\mathrm{mg} / \mathrm{dl})$ & LDLC: HDLC \\
\hline $\mathrm{NC}(\mathrm{n}=15)$ & $170 \pm 34$ & $142 \pm 51$ & $38 \pm 10$ & $98 \pm 25$ & $2.67 \pm 0.92$ \\
$\mathrm{DC}(\mathrm{n}=12)$ & $175 \pm 37$ & $150 \pm 48$ & $34 \pm 8$ & $109 \pm 30$ & $3.49 \pm 1.66$ \\
$\mathrm{EH}(\mathrm{n}=18)$ & $167 \pm 44$ & $145 \pm 70$ & $37 \pm 13$ & $111 \pm 27$ & $3.36 \pm 1.35$ \\
$\mathrm{DH}(\mathrm{n}=12)$ & $182 \pm 32$ & $183 \pm 70$ & $35 \pm 8$ & $118 \pm 3$ & $3.54 \pm 1.34$ \\
t/p values & & & & & \\
NC vs DC & $-0.35 / 0.732$ & $-0.43 / 0.669$ & $1.45 / 0.159$ & $-1.01 / 0.326$ & $-1.64 / 0.144$ \\
$\mathrm{NC}$ vs EH & $0.22 / 0.825$ & $-0.15 / 0.879$ & $0.61 / 0.544$ & $-1.34 / 0.189$ & $-1.74 / 0.092$ \\
$\mathrm{NC}$ vs DH & $-0.88 / 0.387$ & $-0.28 / 0.785$ & $1.23 / 0.229$ & $-1.68 / 0.108$ & $-1.92 / 0.070$ \\
DC vs EH & $0.52 / 0.605$ & $0.23 / 0.816$ & $-0.68 / 0.503$ & $-0.14 / 0.891$ & $0.23 / 8.24$ \\
DC vs DH & $-0.46 / 0.652$ & $-1.31 / 0.204$ & $-0.26 / 0.796$ & $-0.67 / 0.509$ & $-0.08 / 0.934$ \\
EH vs DH & $-1.02 / 0.316$ & $-1.42 / 0.167$ & $0.47 / 0.645$ & $-0.62 / 0.543$ & $-0.36 / 0.721$ \\
\hline
\end{tabular}

Results are expressed as mean \pm SD. Statistical difference- calculated between two groups by unpaired student's 't' test 


\section{Discussion:}

Calcium is the most abundant in the human body. In its ionized form, calcium is involved in a wide range of physiological function and serves as a novel second messenger affecting enzyme activity and hormonal secretion ${ }^{11}$. Estimation of serum ionized calcium is very important to evaluate the calcium status in the body. Inspite of the importance of the calcium ion in serum no attempt so far has been made to measure serum ionized calcium in Bangladesh. The present study is the first attempt to introduce the standardize the measurement using an up to date technique. Result of serum $\mathrm{Ca}^{2+}$ (Table II) in 15 healthy control (NC) subjects show that the range obtained in the normal subjects $(1.14-1.20 \mathrm{mmol} / \mathrm{l})$ was very much within the internationally accepted normal value $(1.15-1.35 \mathrm{mmol} / \mathrm{l})^{12}$. Although the sample size is small, it provides a valuable guideline for future large scale studies to establish the reference ranges of serum $\mathrm{Ca}^{2+}$ in various age-sex groups of our population. The present finding consistent with the previous finding [ref] where no change of serum $\mathrm{Ca}^{2+}$ is observed in $\mathrm{EH}$ subjects. Others suggested the difference with the result, may be due to racial variation. Earlier it was suggested that serum glucose may alter cellular calcium ion homeostasis in hypertensive and in vascular diseases [ref]. The finding of similar serum $\mathrm{Ca}^{2+}$ in all the groups of subjects with widely varying glucose levels between diabetic and non diabetic groups (Table II) seem to contradict the above view supporting this idea no correlation was found between serum glucose and $\mathrm{Ca}^{2+}$ levels. However, it does not exclude increased intracellular turnover of $\mathrm{Ca}^{2+}$ where the steady state of serum $\mathrm{Ca}^{2+}$ may remain unchanged. Moreover it was found that though the diabetic control and Diabetic hypertensive groups had elevated level of insulin but they had similar ionized calcium levels. These seem to preclude any role of elevated insulin level on serum ionized calcium. Again, however, increased turnover of $\mathrm{Ca}^{2+}$ in cells can not be excluded by the present results. All the four groups had comparable serum $\mathrm{Ca}^{2+}$ level indicating that neither hypertension nor diabetes affects the basal levels of the cation in the serum.

\section{Conclusion:}

The data suggest the following conclusions: a) Serum ionized calcium level in our population is similar to that reported for other population. b) Serum glucose and insulin by themselves do not have any direct influence on serum ionized calcium. c) Non obese diabetes mellitus subjects in our population do not show insulin resistance as the primary defect. Rather, there is significant decompensation of the insulin secretory capacity in the subjects. d) Insulin resistance should be measured directly in relation to blood pressure and $\mathrm{Ca}^{2+}$ in appropriate groups of subjects to explore the relationship between insulin resistance, hyperinsulinemia and serum ionized calcium.

\section{References:}

1. WHO Technical reports series, TRS 686, Geneva, 1983.

2. Malik A. Bangladesh Med Coun Bull 1976; 115-119.

3. Gordon HW. Hypertensive vascular disease. Harrison's Principles of Internal Medicine. New York, Mc Graw Hill Inc, 1994; pp1116-1131.

4. Repak TJ and Villar J. Pregnancy-induced hypertension and low birth weight: the role of calcium. Am J Clin Nutr 1991; 54: 237s-146s.

5. Cutler JA and Brittain E. Calcium and blood pressur, an epidemiologic perspective. Am J hypr 1990; 3: 137s-146s.

6. Cooper RS, Shamsi N. Ionized serum calcium in black hypertensice absence of relationship with blood pressure. J Clin Hypertens 1987; 3 (4): 514-519.

7. Ferrani, Buzzigoli G, Bonadona R, Giorico AM, Oleggini M, Graziadei L, Pedrinelli R, Brandi L and Bevilacqua $\mathrm{S}$. Insulin resistance in essential hypertension. $N$ Engl J Med 1987; 317: 350-357.

8. Defronzo RA and Ferrannini E. A multifaceted syndrome responsible for NIDDM, Obesity, Hypertension, Dyslipidemia and Atherosclerotic cardiovascular disease. Diabetes Care 1991; 14: 173-94.

9. Mbanya J-Cn, Toomas TH, Wilkinson R, Alberti KGMM and Taylor R. Hypertension and hyperinsulinaemia: a relation in diabetes but not essential hypertension. Lancet 1988; 1: 733-34.

10. Zamel BM, Soweres RJ, Shehin S, Walsh FM and Levy J. Impaired calcium metabolic associated with hypertension in Zucker Obese rats. Metabolism 1990; 39: 704-708.

11. Chattopadhyay N, Mithal A and Brown EM. The calcium-sensing receptor: A window into the physiology and pathophysiology of mineral ion metabolism. Endocrine Reviews 1996; 17: 289-307.

12. Endres DB and Rude RK. Mineral and bone Metabolism In: Burtis CA and Ashwood ER (eds); 1996: pp 685-702. 